\title{
Brain in human nutrition and variant Creutzfeldt-Jakob disease risk (vCJD): detection of brain in retail liver sausages using cholesterol and neuron specific enolase (NSE) as markers
}

\author{
E. Lücker ${ }^{1 *}$, S. Horlacher ${ }^{2}$ and E. Eigenbrodt ${ }^{3}$ \\ ${ }^{1}$ Institute of Food Hygiene, University of Leipzig, An der Tierkliniken 35, 04103 Leipzig, Germany \\ ${ }^{2}$ Institute of Veterinary Food Science, Justus-Liebig University, Giessen, Frankfurter St 92, 35392 Giessen, Germany \\ ${ }^{3}$ Institute of Biochemistry and Endocrinology, Justus-Liebig University, Giessen, \\ Frankfurter St 100, 35392 Giessen, Germany
}

\begin{abstract}
No information is available about the consumption of brain via meat products. With respect to the new variant of Creutzfeldt-Jakob disease (vCJD) and the presumed food-borne transmission of bovine spongiform encephalopathy (BSE) to humans, a preliminary survey for brain and/or spinal cord (tissues of the central nervous system, CNS) was conducted. We applied a previously developed integrated procedure using cholesterol and neuron specific enolase (NSE) as markers. Quantification of cholesterol had to be backed up by NSE immunochemistry in order to account for low specificity and relatively high variances. Out of 126 high-quality finely graded liver sausages, five samples (4\%) showed positive NSE immunoresponses. In four of these samples a transgression of the normal maximum cholesterol content was obtained. The identification of such a considerable number of CNS-positive sausages indicates that brain consumption is not as rare as previously assumed. Overall, the present integrated method could be successfully applied for the detection of CNS in heat-treated meat products. Its routine application in official food control would deter illegal practice and thus help to control transmissible spongiform encephalopathies.
\end{abstract}

Brain in human nutrition: Meat products: Transmissible spongiform encephalopathies

Brain is assumed to be an extremely rare and exotic component in human nutrition. In 1957, the consumption of brain during ritualistic cannibalism was associated with the transmission of kuru, a human spongiform encephalopathy of some Fore tribes in Papua New Guinea (Gajdusek, 1977). The appearance after 1986 of new, presumably feedborne, forms of transmissible spongiform encephalopathy (TSE) in bovines (BSE), in exotic ungulates, and in felines led to the assumption that humans might be infected via bovine brain entering the human food chain. This was substantiated when in 1996 the first 10 cases of a new variant of Creutzfeldt-Jakob disease (vCJD) were described (Will et al. 1996). It must be assumed that the greatest risk, if any, was posed by meat products produced with substantial amounts of bovine brain and/or spinal cord (tissues of the central nervous system, CNS): 1, Infectivity titres of bovine CNS exceed that of any other tissues up to several orders of magnitude (SSC, 1998); 2, weight of CNS (adult bovines: 630-740 g; Seiferle, 1992) exceeds that of the few other tissues showing high infectivity titres by at least 1 order of magnitude; 3 , the use of CNS in the meat processing industry is of some interest considering its high content of substances with emulgating properties, high nutritional value, low price, and ready availability (mechanical deboning of skulls and vertebral column); 4, it is estimated that 840 000-1 250000 infected animals were allowed to enter the human food chain, as BSE infectivity is present for a considerable time before the onset of clinical symptoms and the measures taken to enforce the ban were to some extent ineffective (Anderson et al. 1996). However, industry disclaims and, in many countries, law or food codes prohibit the addition of CNS to meat products. Whether brain and spinal cord of slaughtered animals were actually used in the manufacture of meat products during the critical period prior to the ban of specified bovine offal (UK Government, 1989) is a matter of speculation as methods for their detection were missing at that time. Recently, it was demonstrated that cholesterol and neuron specific enolase (NSE, Table 1) could be used as markers for CNS in heat-treated meat products (Lücker et al. 1999). These studies used mainly in-house reference materials with known addition of CNS and only a few field samples from local retail outlets. Thus, the present study was designed as a survey for CNS addition in retail meat products currently on the market in Germany. We chose high quality, finely ground cooked liver sausages as the use

* Corresponding author: Dr E. Lücker, fax +49 34197382 49, email luecker@vmf.uni-leipzig.de 
Table 1. Use, content and frequency of selected ingredients in meat products and contents of cholesterol (mg/100 $\mathrm{g}$ fresh product) and of neuron specific enolase (NSE, $\mathrm{ng} / \mathrm{mg}$ soluble protein) as reported in literature

\begin{tabular}{|c|c|c|c|}
\hline Ingredient & Use (content, frequency) & Cholesterol & NSE \\
\hline Brain & Not allowed in most products ${ }^{a}(1-20 \%, ?)$ & $2223 \pm 271^{d}$ & $11200 \pm 3200^{\circ}$ \\
\hline Spinal cord & Not allowed ${ }^{\mathrm{a}}(?)$ & $2420 \pm 310^{\mathrm{e}}$ & $13000 \pm 1000^{\circ}$ \\
\hline Dorsal root ganglia & Via mechanically deboned meat (?) & - & $831-1145^{b}$ \\
\hline Optic nerve & Via mechanically deboned meat (?) & - & $4200-7800^{b}$ \\
\hline Peripheral nerves & Technologically unavoidable (?) & - & $59-765^{\mathrm{b}}$ \\
\hline Muscle & Main component (20-100\%, obligatory) & $69 \pm 7^{d}$ & $29 \pm 5^{\mathrm{c}}$ \\
\hline Adipose tissue & Usual component (2-50\%, obligatory) & $72 \pm 4^{\mathrm{d}}$ & $47 \pm 25^{\mathrm{c}}$ \\
\hline Heart & Some products $(1-5 \%$, rare $)$ & $146 \pm 11^{d}$ & $40 \pm 21^{c}$ \\
\hline Liver & Liver sausages (10-30\%, frequent) & $365 \pm 82^{d}$ & $8 \pm 5^{\mathrm{c}}$ \\
\hline Blood & Blood sausages (10-20\%, frequent) & $106 \pm 40^{\mathrm{d}}$ & $189 \pm 14^{f}$ \\
\hline Kidney & Not allowed in most products ${ }^{\mathrm{a}}(1-5 \%$, rare $)$ & $376 \pm 12^{d}$ & $15 \pm 9^{c}$ \\
\hline Lung & Not allowed in most products ${ }^{a}(1-5 \%$, rare $)$ & $239 \pm 72^{d}$ & $28 \pm 17^{c}$ \\
\hline Yolk & Not allowed in most products ${ }^{a}(1-5 \%$, rare) & $1260^{\mathrm{d}}$ & - \\
\hline
\end{tabular}

-: not given; where possible mean and standard deviation are given as reported (including interspecies variations in ${ }^{\mathrm{d}}$ ).

of CNS in these products would be of some technological advantage with respect to its emulgating properties. However, according to the German Food Code (2000), CNS is not allowed in the production of these sausages.

\section{Materials and methods}

\section{Field samples}

A total of 126 cooked liver sausages were obtained on the occasion of the 1998 quality testing of cooked products and lard by the German Agricultural Society (Hildebrandt \& Kleer, 1998). All of the samples had a thoroughly homogeneous appearance (finely ground cooked liver sausages) and had been produced using moderate heating (storage stability: several days at $\leq 10^{\circ} \mathrm{C}$ ). The sausages were of high quality which excluded the use of other offals besides liver according to the German Food Code (2000). The mode of sampling was totally randomised with manufacturer and provenance unknown to the sampling personnel. In addition, we used a further 76 samples as a negative control group. These included various types of cooked liver sausages: finely and coarsely ground; low to high quality; with and without addition of further ingredients such as onions. They were obtained from locally known and reliable butchers where the possibility of CNS addition could be excluded in all probability.

\section{Reference materials}

Reference material as used in this study was manufactured with defined addition of bovine brain following the usual recipe for cooked liver sausages. A basic filling was produced using a high-performance table-top laboratory cutting mixer (Diana-63004, Dianawerk, Kassel, Germany). The basic filling was composed of $1.0 \mathrm{~kg}$ pork trimmings from belly, shoulder and cheek (mean fat content: $40 \%$ ), $0 \cdot 2 \mathrm{~kg}$ drinking water as substitution for the preboiling loss, and $0.02 \mathrm{~kg}$ curing salt $\left(4-5 \mathrm{~g} / \mathrm{kg} \mathrm{NaNO}{ }_{2}\right.$ in $\mathrm{NaCl}$, Enders, Reiskirchen, Germany). The meat was preboiled at $90^{\circ} \mathrm{C}$ over $60 \mathrm{~min}$, shortly cooled and processed at approx. $2900 \mathrm{rpm}$ in the cutting mixer until a totally homogenous material was obtained. Hot water was added during the final part of homogenisation. Then the basic filling was homogenised with $16 \%$ (or $15 \%$ ) of prehomogenised porcine liver and varying amounts $(0 \cdot 0,0 \cdot 25,1 \cdot 0,2 \cdot 0,4 \cdot 0)$ of prehomogenised bovine brain using a kitchen mixer (Moulinette, Kalensee, Gießen, Germany). The material was filled into tins $(150 \mathrm{ml})$ which were closed and heated for $60 \mathrm{~min}$ at $80^{\circ} \mathrm{C}$ in the steam heater. Reference material was analysed as control along with the field samples in both quantification of cholesterol and NSE immunochemistry.

\section{Quantification of cholesterol}

Quantification of cholesterol was achieved by use of the enzymatic testkit from Roche/Boehringer (Mannheim, Germany) for spectrophotometry (Anonymous, 1995); sample preparation and extraction in methanolic $\mathrm{KOH}$ were performed according to the guidelines as given for liver sausage. The test principle is based on the 3- $\beta$ oxidation of cholesterol to $\Delta^{4}$-cholestenone. The resulting $\mathrm{H}_{2} \mathrm{O}_{2}$ oxidises methanol to formaldehyde in the presence of katalase. Subsequently a yellow lutidine dye is formed which is spectrophotometrically (Hitachi U2000) quantified at $405 \mathrm{~nm}$.

\section{NSE immunochemistry}

Proteins were extracted from the sample matrix using trisurea buffer at $4^{\circ} \mathrm{C}$ and a Potter-Elvehjem homogeniser (Novodirect, Kehl/Rhein, Germany), centrifuged at $14000 \mathrm{rpm}$ for $10 \mathrm{~min}$, filtered, and diluted 15:1 (v/v) in sample buffer (tris-SDS-mercaptoethanol-urea). The proteins were separated by means of SDS gel electrophoresis using $10 \%$ acrylamide gel (PAGE) according to Laemmli (1970) and then transferred on PVDF membranes (Millipore, Bedford, MA) using an electroblot apparatus (Biotec-Fischer, Reiskirchen, Germany). Following incubation in blocking solution (BS: phosphate buffered saline with $1 \%(\mathrm{w} / \mathrm{v})$ bovine serum albumin and $0.2 \%(\mathrm{v} / \mathrm{v})$ Tween 20, pH 7.4; Merck, Darmstadt, Germany) for $1 \mathrm{~h}$, the membranes were incubated overnight at room temperature with monoclonal anti-NSE antibodies (Dako, 
Hamburg, Germany; clone BBS/NC/VI-H14). Then, the membranes were incubated with biotinylated goat antimouse antibodies (Zymed, San Francisco) diluted 1:2000 in $\mathrm{BS}$ over $1 \mathrm{~h}$ and then incubated with peroxidase-conjugated streptavidin (Zymed, San Francisco) over 60 min. Staining was achieved by adding $\mathrm{H}_{2} \mathrm{O}_{2}$ (Merck, Darmstadt, Germany) and DAB (3,3'-diaminobenzidine-tetrathydrochloridhydrate, Aldrich, Milwaukee, USA).

\section{NSE immunoresponse}

Quantification of NSE immunoresponse was achieved by densitometric analysis (Scion Image, Release Beta 3b, Scion Corporation, Frederick, Maryland) of digitalised immunoblots. Peak area integrations were expressed in relation to the respective standard (non-heated liver sausage containing $1 \%$ bovine brain) as analysed within the same immunoblot.

\section{Computation}

Statistical analysis of cholesterol data included the $W$ statistic (Shapiro and Wilks' statistic), the two-group t-test and the non-parametric Mann-Whitney (Wilcoxon) ranksum test; computation was performed using the programs BMDP 2D and 3D (Dixon, 1993). MS-Excel 97 was used for any further calculations. Cutoff points $\left(x_{C P}\right)$ for the upper limits of normal maximum cholesterol content were calculated according to the following equation: $x_{C P}=$ $\bar{x}+z \times s$, where $\bar{x}$ is the arithmetic mean cholesterol content of the samples and $s$ the respective standard deviation in milligrams per 100 grams; $z$ is the bounds of the standard normal distribution with $z=$ $1.645(P=0.05$, one-sided $)$.

\section{Results}

Arithmetic mean $(\bar{x})$ and standard deviation $(s)$ of the cholesterol contents of the 126 liver sausages were 123 and $31 \mathrm{mg} / 100 \mathrm{~g}$ fresh product, respectively. The results ranged from $x_{\text {Min }}=59$ to $x_{\text {Max }}=297 \mathrm{mg} / 100 \mathrm{~g}$ with a median $(\tilde{x})$ of $120 \mathrm{mg} / 100 \mathrm{~g}$ fresh product. Two-thirds of the samples had cholesterol contents below 130 and $90 \%$ below $156 \mathrm{mg} / 100 \mathrm{~g}$ fresh product. Thus, the distribution was found to be skewed to the left as shown in Fig. 1. The Shapiro and Wilkes' test gave a $W$ statistic of 0.91 and showed a highly significant deviation from the normal distribution $(P<0 \cdot 001)$. Both approaches - iterative reduction of maxima until normality of distribution was reached and retrospective reduction of CNS-positive samples - yielded cutoff points for normal maximum cholesterol content $(P=0.05)$ of $160 \mathrm{mg} / 100 \mathrm{~g}$ fresh product. Following elimination of samples presumably adulterated with CNS, the distribution of the cholesterol contents in liver sausages was characterised as follows: $\bar{x}=119, s=24, \tilde{x}=120, x_{\text {Min }}=59, x_{\text {Max }}=181 \mathrm{mg} / 100 \mathrm{~g}$ fresh product. Results were significantly lower $(P<0.001$, $\mathrm{t}$ test, Mann-Whitney test) than those obtained in the control group, where $\bar{x}=150, s=21, \tilde{x}=151, x_{\text {Min }}=92$, $x_{\text {Max }}=186 \mathrm{mg} / 100 \mathrm{~g}$ fresh product. The corresponding

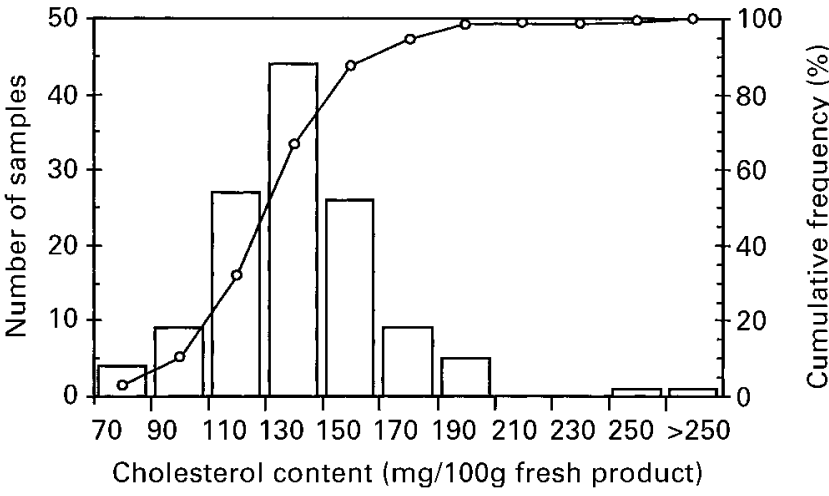

Fig. 1. Absolute and cumulative frequency of cholesterol in 126 cooked liver sausages as analysed by a colorimetric assay.

cutoff point for normal maximum cholesterol content in the control group was $187 \mathrm{mg} / 100 \mathrm{~g}(P=0 \cdot 05)$. Results of the reference material (15\% liver, no brain addition) as analysed along with the field samples were $\bar{x}=102, s=$ 5.9 , and ranged from 92 to $105 \mathrm{mg} / 100 \mathrm{~g}$ fresh product. The expected cholesterol content of the endproduct as calculated from the its components, the filling $(90 \mathrm{mg} / 100 \mathrm{~g})$ and the liver $(274 \mathrm{mg} / 100 \mathrm{~g})$, was $118 \mathrm{mg} / 100 \mathrm{~g}$ fresh product.

All results as obtained for the cooked liver sausage reference material $(0,0 \cdot 25,1,2,4 \%$ brain $)$ with SDSPAGE and Western blotting, using monoclonal anti-NSE antibodies, were in accordance with previous findings, i.e. no false positive or false negative results were obtained and immunoreactivity was closely correlated to the amount of brain present in the sample. It was noted, however, that the intensity of the immunoresponses varied in some cases considerably between immunoblots. This is demonstrated in Fig. 2 which shows the $50 \mathrm{kDa}$ NSE band for ten samples and their respective (non-heated) reference material with a brain content of $1 \%$. We obtained positive immunoresponses in five out of the 126 field samples $(4.0 \%)$. This was correlated in four cases with a transgression of the cutoff point for normal cholesterol content, whereas the cholesterol content of sample No. 45 was only $90.6 \%$ of the cutoff point. The cholesterol content of $7(5.6 \%)$ samples transgressed the cutoff point of $160 \mathrm{mg} / 100 \mathrm{~g}$ with $\bar{x}=172, s=6.4, \quad x_{\text {Min }}=164$, $x_{\operatorname{Max}}=181 \mathrm{mg} / 100 \mathrm{~g}$ fresh product. With respect to varying immunoresponses, the intensity of each sample band was calculated in relation to the band of the respective reference material (1\% CNS addition, non-heated) in the same immunoblot. The relative intensity of the immunoresponses (Fig. 2) proved to correlate moderately with the respective cholesterol contents $\left(r^{2}=0 \cdot 70\right.$, with $y=0.0036 x-0.46)$.

\section{Discussion}

In contrast to the previous results obtained for emulsion type sausages (Lücker et al. 1999), the present study indicated that a cutoff point for the maximum normal 


\begin{tabular}{|c|c|c|c|c|}
\hline \multirow{2}{*}{$\begin{array}{l}\text { Sample } \\
\text { no. }\end{array}$} & \multirow{2}{*}{$\begin{array}{l}\text { Cholesterol } \\
\text { content } \\
(\mathrm{mg} / 100 \mathrm{~g})\end{array}$} & \multicolumn{2}{|c|}{ NSE-Immunoblot } & \multirow[b]{2}{*}{$\begin{array}{l}\text { Relative } \\
\text { intensity }\end{array}$} \\
\hline & & Sample & $\begin{array}{l}\text { Reference } \\
\text { material }\end{array}$ & \\
\hline 95 & 97 & & & 0.000 \\
\hline 5 & 104 & & & 0.000 \\
\hline 46 & 145 & 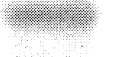 & & $0 \cdot 153$ \\
\hline 96 & 146 & & & 0.000 \\
\hline 60 & 150 & & & 0.000 \\
\hline 64 & 159 & & & 0.000 \\
\hline 92 & 177 & i. & & 0.328 \\
\hline 36 & 182 & & & 0.037 \\
\hline 21 & 245 & 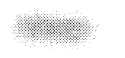 & 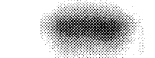 & $0 \cdot 239$ \\
\hline 51 & 297 & & & $0 \cdot 819$ \\
\hline
\end{tabular}

Fig. 2. Cholesterol content in cooked liver sausages and detection of neuron specific enolase (NSE) in the western blot using monoclonal antiNSE antibodies. The relative intensity is the densitometric intensity of the immunoresponses of the sample in relation to that of the respective reference material (non-heated sausage filling with $1 \%$ addition of bovine brain) in the same immunoblot.

cholesterol content in cooked liver sausages cannot be safely established when combining the detection of low brain contents $(<1.0 \%)$ with high statistical security. In order to detect $1.0 \%$ brain in cooked liver sausages, the cutoff point has to be drastically reduced, i.e. from $160 \mathrm{mg} / 100 \mathrm{~g}(P=0.05)$ to $140 \mathrm{mg} / 100 \mathrm{~g}(P=0 \cdot 20)$. The low sensitivity might be a result of the additional variance due to varying amounts of liver and their varying cholesterol contents (Table 1). However, the results of NSE immunochemistry demonstrated cholesterol to be a suitable marker for CNS, albeit for screening purposes, especially if more sophisticated methods are not available. In Germany, this method has already been established in official food control for the quantification of cholesterol in egg and egg products (BgVV, 1992). The method itself had been described by Röschlau et al. (1974) long before the BSE crisis and thus could have been applied to support the ban of specified bovine offal. Pertaining to the relatively low specificity of the cholesterol quantification (Table 1), NSE immunochemistry is needed to confirm CNS adulteration of suspect samples. Reference material was correctly classified when NSE was used as a marker without exception, as was the case in previous studies (Lücker et al. 1999). This is of particular interest with respect to the presence of NSE in peripheral nerves found within muscle tissue (Table 1). In the present and previous studies, the reference material produced without addition of CNS never showed NSE immunoresponses, irrespective of composition (pure muscle or mixture of muscle and adipose tissue) and technology (heated or non-heated). Furthermore, with respect to preventive consumer protection, substantial amounts of peripheral nerve tissue are unwanted in meat products - even though BSE infectivity could not be demonstrated so far in this tissue. Thus a positive NSE immunoresponse due to peripheral nerves should not $a$ priori be classified as a false negative result. Although there remains no doubt regarding the high specificity of NSE immunochemical detection of CNS in meat products, it is not clear whether sensitivity is adequate to account for possible reduction of NSE immunoreactivity due to technological effects, especially heat treatment. First results showing this to be the case (Lücker et al. 2000) emphasise the need for further studies specifically addressing the need for further studies regarding methodological optimisation. 


\section{Conclusion}

The detection of a considerable number of CNS-positive field samples indicate that the use of brain in meat products is neither rare nor exotic in Germany. The use of brain and/ or spinal cord in the production of sausages is in distinct contrast to the general expectation as founded on the lessons learned during the BSE crisis. It stands in further contrast to the disclaimer of the meat industry and to the prohibition by law. The general application of the presented methods in official food control might deter illegal practice and thus help to control transmissible spongiform encephalopathies.

\section{Acknowledgements}

The authors would like to thank Mrs E. Hornung, Ms B. Rühl and Ms U. Langhorst for their valuable technical assistance in parts of this study.

\section{References}

Anderson RM, Donelly CA, Ferguson NM, Woolhouse MEJ, Watt CJ, Udy HJ, MaWhinney S, Dunstan SP, Southwood TRE, Wilesmith JW, Ryan JBM, Hoinville LJ, Hillerton JE, Austin AR \& Wells GAH (1996) Transmission dynamics and epidemiology of BSE in British cattle. Nature 382, 779-788.

Anonymous (1995) Colorimetric method for the determination of cholesterol in foodstuffs and other material. Roche/Boehringer, Mannheim, Germany no. 139050.

$\mathrm{BgVV}$, Bundesinstitut für gesundheitlichen Verbraucherschutz und Veterinärmedizin (Federal Institute of Health, Consumer Protection and Veterinary Medicine) (1992) Bestimmung des Cholesteringehaltes in Eiern und Eiprodukten. Enzymatisches Verfahren. In Amtliche Sammlung von Untersuchungsverfahren nach $\$ 35$ LMBG, L-05.00-17. Berlin: Beuth Verlag.

Dixon WJ (1993) BMDP Statistical Software Manual. Berkley: University of California Press.

Gajdusek DC (1977) Unconventional viruses and the origin and disappearance of kuru. Science 197, 943-960.

German Food Code (2000) Guiding principles for meat and meat products. Bundesanzeiger, pp. 47-148. Köln.
Hildebrandt G \& Kleer J (1998) Kochwurst, gegarte Stückware und Schmalz. Fleischwirtschaft 78, 1120-1129.

Kato K, Ishiguro Y, Suzuki J, Ito A \& Semba R (1982) Distribution of nervous system-specific forms of enolase in peripheral tissues. Brain Research 237, 441-448.

Laemmli UK (1970) Cleavage of structural proteins during the assembly of the head of bacteriophage T4. Nature 227, 680-685.

Lücker E, Eigenbrodt E, Wenisch S, Failing K, Leiser R \& Bülte M (1999) Development of an integrated procedure for the detection of central nervous tissue in meat products using cholesterol and neuron-specific enolase as markers. Journal of Food Protection 62(3), 268-276.

Lücker E, Eigenbrodt E, Wenisch S, Leiser R \& Bülte M (2000) Identification of central nervous system tissue in retail meat products. Journal of Food Protection 63(2), 258-263.

Marangos PJ, Schmechel D, Parma AM, Clark RL \& Goodwin FK (1979) Measurement of neuron-specific (NSE) and nonneuronal (NNE) isoenzymes of enolase in rat, monkey and human nervous tissue. Journal of Neurochemistry 33, 319-329.

Röschlau P, Bernt E \& Gruber W (1974) Methoden der enzymatischen Analyse, 3rd edn., vol. 2, pp. 1938-1941 [HU Bergmeyer, editor]. Weinheim: Verlag Chemie.

Runquist M, Parmryd I, Thelin A, Chojnacki T \& Dallner G (1995) Distribution of branch point prenyltransferases in regions of bovine brain. Journal of Neurochemistry $\mathbf{6 5}$, 2299-2306

SSC, Scientific Steering Committee (1998) Listing of specified risk materials: a scheme for assessing relative risks to man Opinion of the Scientific Steering Committee adopted on 9 December 1997. http://europa.eu.int/comm/dg24/health/sc/ssc/ outcome_en.html.

Seiferle E (1992) Lehrbuch der Anatomie der Haustiere, 3rd edn., vol. 4, pp. 27-59 [R Nickel, A Schummer and E Seiferle, editors]. Berlin: Paul Parey Verlag.

Souci SW, Fachmann W \& Kraut H (1994) Food Composition and Nutrition Tables, 5th edn., Stuttgart: Medpharm Scientific Publishers

UK Government (1989) The bovine offal (prohibition) regulations. United Kingdom SI no. 2061.

Will RG, Ironside JW, Zeidler M, Cousens SN, Estibeiro K, Alperovitch A, Poser S, Pocchiari M \& Hofman A (1996) A new variant of Creutzfeldt-Jakob disease in the UK. Lancet 347, 921-925. 